\title{
Rape, consent and a lie about fertility: $R v$ Lawrance [2020] EWCA Crim 971
}

Article

Accepted Version

Krebs, B. (2020) Rape, consent and a lie about fertility: R v Lawrance [2020] EWCA Crim 971. Journal of Criminal Law, 84 (6). pp. 622-625. ISSN 1740-5580 doi:

https://doi.org/10.1177/0022018320976662 Available at https://centaur.reading.ac.uk/100411/

It is advisable to refer to the publisher's version if you intend to cite from the work. See Guidance on citing.

Published version at: https://doi.org/10.1177/0022018320976662

To link to this article DOI: http://dx.doi.org/10.1177/0022018320976662

Publisher: SAGE

All outputs in CentAUR are protected by Intellectual Property Rights law, including copyright law. Copyright and IPR is retained by the creators or other copyright holders. Terms and conditions for use of this material are defined in the End User Agreement.

\section{www.reading.ac.uk/centaur}

\section{CentAUR}

Central Archive at the University of Reading

Reading's research outputs online 


\title{
Rape, Consent and a Lie about Fertility
}

\author{
$R v$ Lawrance [2020] EWCA Crim 971 (23 July 2020)
}

Keywords: consent; deception; fertility; non-disclosure; rape; vasectomy

This was an appeal against a rape conviction. The appellant had met the complainant on a dating website. During a sexually explicit exchange of messages, he claimed to have had 'the snip'. The complainant gave evidence that before they had sexual intercourse during a subsequent meeting at her home, she had sought an assurance that the appellant had indeed had a vasectomy. He assured her that he had. She made it clear that she did not want to risk becoming pregnant. He repeated his assurance, and the complainant proceeded twice to have sex with him without the use of contraception. The next day, the appellant sent her a message, telling her that he was still fertile. The complainant then discovered that she was pregnant and had a termination.

It was the prosecution's case that the complainant's consent to sexual intercourse was vitiated by the appellant's deception about having had a vasectomy and that even if he had genuinely believed that she had consented, such a belief was unreasonable.

It was the defence case that a lie about fertility could not, as a matter of law, vitiate consent, even if relied upon by the complainant. In order to vitiate consent a deception had to go to the nature of the sexual act or be closely connected to the sexual act. In the present case the deception did not fit into either category. The decisions in Assange $v$ Swedish Prosecution Authority [2011] EWHC 2849 (Admin) (deceit as to the wearing of a condom vitiated consent) and $R(F) v D P P$ [2014] QB 581 (deceit as to intended withdrawal vitiated consent) could be distinguished on the basis that in those cases consent had been given on the basis that ejaculate would be prevented from entering the complainants' vaginas, whereas in the present case that was not sought to be avoided. The appellant's deceit went to the consequences of intercourse, rather than the performance of the act itself, and could therefore not negate consent.

The trial judge ruled that a deception about fertility was capable of negating consent and the appellant was found guilty. He appealed against his conviction on two counts of rape (he had been convicted of further sexual offences, including rape, against other women but these did not form part of the present appeal).

Held, allowing the appeal and quashing the appellant's convictions on two counts of rape, that the appellant's deception about his fertility was not capable in law of negating consent (at [43]). The Court accepted that the jury must have concluded that the complainant had relied on the appellant's deception and that she would not have consented to unprotected sexual intercourse had she thought him to be fertile. However, the 'but for' test was insufficient of itself to vitiate consent. There might be many circumstances in which a complainant was deceived about a matter which was central to her choice to have sexual intercourse [the court proceeded to give examples, including lies about marital status, political or religious views, employment or wealth] (at [34]). The question was whether a lie as to fertility was so closely connected to the nature or purpose of sexual intercourse, rather than the broad circumstances surrounding it, that it was capable of negating consent (at [35]). 
In the court's opinion, a lie about fertility was different from a lie about whether a condom was being worn during sex, different from engaging in intercourse not intending to withdraw having promised to do so and different from engaging in sexual activity having misrepresented one's gender (at [36]).

Unlike the woman in Assange, or in $R(F)$, the complainant in the present case had agreed to sexual intercourse with the appellant without imposing any physical restrictions. She agreed both to vaginal penetration and to ejaculation without the protection of a condom. In so doing she was deceived about the nature or quality of the ejaculate and therefore of the risks and possible consequences of unprotected intercourse. The deception was one which related not to the physical performance of the sexual act but to risks or consequences associated with it (at [37]). In terms of s. 74 of the 2003 Act, the complainant was not deprived by the appellant's lie of the freedom to choose whether to have the sexual intercourse which occurred (at [38]).

The court found force in the appellant's submission of an analogy with $R v B$ [2006] EWCA Crim 2945 where the accused had failed to disclose that he was HIV positive prior to having sexual intercourse with the complainant. The transmission of the disease through sexual intercourse was not part of the performance of the sexual act but a consequence of it (at [39]). It made no difference to the issue of consent whether, as in this case, there was an express deception or, as in the case of $R v B$, a failure to disclose. The issue was whether the appellant's lie was sufficiently closely connected to the performance of the sexual act, rather than the broad circumstances surrounding it, and in the present case it was not (at [41]).

The court observed that arguments about consent in cases of alleged sexual offending sometimes proceeded on the assumption that the meaning of "consent" was a matter for development by the common law. That was no longer the position because consent was defined in section 74 of the 2003 Act, with the evidential presumptions found in section 75 and the conclusive presumptions in section 76. Any novel circumstances had to be considered by reference to the statutory definition, namely whether the alleged victim has agreed by choice and has the freedom and capacity to make that choice. There was no sign that Parliament had intended a sea change in the meaning of consent when it legislated in 2003 (at [42]).

\section{Commentary}

Deception as a consent-vitiating factor remains a difficult issue for the sexual offences and rape in particular. The case law has been clear for some time now that consentvitiating deceptions do not remain restricted to the circumstances specified in s. 76 of the Sexual Offences Act 2003 (i.e. deceptions that go to the nature or purpose of the sexual act or amount to impersonations of a person personally known to the complainant and which seek to induce the complainant's consent). It has also been clear that not every deception is capable of vitiating consent for the purposes of s. 74 SOA 2003 (according to which a person consents if she agrees by choice and has the freedom and capacity to make that choice). It has been anything but clear, however, where and how to draw the line between deceptions that can and those that cannot vitiate consent. Lawrance is the latest in a (long) line of cases attempting to shed light on this question.

Perhaps one should start with the positives. The instant decision has the merit of simplifying the law by doing away with the distinction between active deceptions and non-disclosures which was difficult to draw in practice. As the court explains: '[D]eceit 
and deception are very slippery concepts which ... may result from a clear short lie, through more obscure utterances, obfuscation or evasion, to conduct designed to convey an unspoken false impression. In this area it is difficult to draw clear principled lines which could distinguish a deceit resulting from one course from another' (at [40]). Although this undermines the reasoning in some earlier cases (see Assange), the court is probably right to conclude that it ought not matter to the issue of (informed) consent whether (as in Lawrance) the deception involved an express lie or rather a failure to disclose (as in $R v B$ where the appellant did not reveal that he was HIV positive). The key issue will always be whether the deceptive conduct mattered, which, in the court's view, will be the case if it 'was sufficiently closely connected to the performance of the sexual act, rather than the broad circumstances surrounding it' (at [41]).

The phrase 'sufficiently connected' indicates that there is a threshold requirement that needs to be satisfied before deceptive conduct triggers its consent-vitiating effect. Working out what the minimum threshold is or ought to be and whether it has been crossed might prove difficult in individual cases. However, the conceptual distinction between active deceptions and non-disclosures was never quite satisfactory, and with it gone, the post-Lawrance law will be simpler and clearer in some respects.

Another welcome development in Lawrance is the court's attempt to rationalise its decision on the basis of legal principle rather than (just) common sense. This sets it favourably apart from some of the earlier case law in this area (e.g. $R(F)$ and McNally [2013] EWCA Crim 1051). Common sense as a general approach to determining whether consent is vitiated had little to commend it (other than it may have helped to achieve what courts and juries intuitively felt to be the right outcome). Of course, over time such a discretionary approach might have seen the establishment of certain case categories; however, without an overarching principle to anchor these and guide their incremental development such an approach always ran the danger of developing the law in an unpredictable ad hoc manner and without a common justifying rationale.

The court in the present case seeks to invoke a principle distilled from previous case law (and $R$ (Monica) v DPP [2018] EWHC 3508 (Admin) in particular, which is not surprising given that Lord Burnett $\mathrm{CJ}$ co-authored both judgements). In doing so, the court draws on the arguments presented on behalf of the appellant whose analysis the judgment largely adopts. The principle identified looks to whether a deception that was material in the 'but for' sense to the complainant's decision to consent is sufficiently closely connected to the nature, purpose or performance of the physical act (rather than the 'broad circumstances surrounding it', see [35]).

This approach is designed to weed out instances where the deception was not relevant to the 'mechanics' of sexual intercourse and thus ought not be criminalised as rape (even though it may have been central to the complainant's decision to consent, see [34]). It is based on the premise that, for example, sex with a wealthy person is no different from sex with a poor person, when viewed from the perspective of the physical act which, on the court's account, involves penile penetration (a key element of rape as defined in s. 1 of the Sexual Offences Act 2003) as well as ejaculation (which is not necessary for rape to occur but an integral part of sexual intercourse as defined by the court). 
Concerns aside that such a narrow view of what factors should, or should not, matter to the issue of consent in the context of rape does not fully protect a complainant's sexual autonomy (for she might well object that her sexual partner's status was essential to her consenting, and, what's more, may have made this abundantly clear by stipulating wealth as a condition precedent for her consent), there is doubt that the principle in Lawrance is suitable in less clear-cut (and more realistic) scenarios, especially those that turn on deceptions about (the need for) contraceptive measures.

In this context, Lawrance seems capable of producing outcomes that are difficult to reconcile: it can be rape if a condom is stealthily removed (Assange); it might be rape if A keeps B in the dark that the condom B insisted they use has split (now that the distinction between active deceptions and non-disclosures is gone); it can be rape if $\mathrm{A}$ promised $\mathrm{B}$ to withdraw before ejaculation, wherefore no condom is requested by $\mathrm{B}$, and $\mathrm{A}$ does not do so and, crucially, never intended to $(R(F))$; but it cannot be rape if A deceitfully led B to believe that a condom is not needed in the first place (Lawrance).

The court has an answer to the apparent inconsistencies; however, its analysis (below) is contrived and ignores the bigger picture (namely, that the women in the aforementioned cases were all aiming to prevent unwanted pregnancies).

For the court, in applying the principle whether a lie 'was sufficiently closely connected to the performance of the sexual act', the key question is whether or not the complainant imposed any 'physical restrictions' (at [37]). And in the court's view, this is how Lawrance can be distinguished (inter alia) from Assange and $R(F)$. On its analysis, the women in Assange and $R(F)$ were seeking to avoid ejaculation, whereas the complainant in Lawrance was content to receive ejaculate, albeit that the ejaculate she expected was to be devoid of sperm. Since ejaculation is part of the physical act, the conditions imposed in Assange (to wear a condom) and $R(F)$ (to withdraw prior to ejaculation) were closely connected with the physical act and the deceptions capable of vitiating consent, whereas the vasectomy lie in Lawrance did not affect the performance of the sexual intercourse but related solely to a consequence thereof, i.e. pregnancy.

In the court's words: 'the complainant in the present case had agreed to sexual intercourse with the appellant without imposing any physical restrictions. She agreed both to penetration of her vagina and to ejaculation without the protection of a condom. In so doing she was deceived about the nature or quality of the ejaculate and therefore of the risks and possible consequences of unprotected intercourse. The deception was one which related not to the physical performance of the sexual act but to risks or consequences associated with it' (at [37], emphasis added).

However, the argument that the complainant was solely deceived about the nature or quality of the ejaculate (and hence the risks and consequences of unprotected intercourse) is misconceived. The deposition of sperm inside the female body is an integral part of sexual intercourse in its most natural form. Contrary to what the appellant argued (see [20]), the complainant in Lawrance did not consent to 'every aspect of the physical act'. By seeking an assurance that the appellant was no longer fertile, and in making it clear (repeatedly on her account) that his alleged vasectomy was a condition for her consent to unprotected sex, she sought to avoid a particular aspect of the physical act: the acquisition of sperm. The court's conclusion that she did not impose any physical restriction on the sexual intercourse does thus not convince. 
Lawrance seeks to streamline the law of consent and, like Monica before it, put it on a more principled footing which is to be welcomed. However, the decision demonstrates that the circumstances in which consent is vitiated can still turn on subtleties that are difficult to justify such as whether a chosen method of contraception would prevent ejaculate from entering the body or just sperm. This is an undesirable state of affairs.

If a condition is truly central to a woman's decision to consent, it now looks as if she might need to frame it explicitly as a restriction on the physical aspects of the sexual act, to ensure that her sexual autonomy can be vindicated should her partner see it fit to ignore the condition.

\section{Beatrice Krebs}

